\title{
Common Fixed Point Theorems for Pair of Self Mapping Satisfying Common (E.A) like Property in Fuzzy Metric Spaces
}

\author{
Bijendra Singh \\ School of studies in Mathematics \\ Vikram University, Ujjain, M.P. (INDIA
}

\author{
Mahendra S. Bhadauriya \\ Vikrant Institute of Technology and Management, \\ Gwalior, M.P. (INDIA)
}

\begin{abstract}
In this paper we prove some common fixed point theorems for a pair of self mappings which possess the common (E.A.) like property and satisfy certain sufficient conditions in the fuzzy metric space. Our result generalized the result of [2].
\end{abstract}

\section{AMS SUBJECT CLASSIFICATION}

$47 \mathrm{H} 10,54 \mathrm{H} 25$

\section{Keywords}

Fuzzy metric space, Compatible maps, Weakly Compatible maps, (E.A.) property, Common (E.A) like property.

\section{INTRODUCTION}

Zadeh [18], investigation of the notion of fuzzy set has laid to the growth of fuzzy mathematics many authors have expansively developed the theory of fuzzy sets and its applications, e.g.see [8] [3] [16] [6] [7] [11] [13].

George and Veeramani [5] introduced the concept of fuzzy metric spaces in different ways. Sushil Sharma [9] obtained common fixed point theorems for for six self mappings satisfying compatibility of type $\alpha$ conditions. Aamir and EI Moutawakil [1] further generalized the concept of non compatibility by introducing the notion of E.A. In this paper we prove some common fixed point theorems for a pair of self mappings which possess the common (E.A.) like property and satisfy certain sufficient conditions in the setting of a fuzzy metric space. It was pointed out that common (E.A) like property allows replacing the completeness requirement of the space with a more natural condition of closeness of the range as well as relaxing the completeness of the whole space, continuity of one or more mappings and containment of the range of one mapping into the range of other which is utilized to construct the sequence of joint iterates, subsequently, there are a number of results proved for contraction mapping satisfying common (E.A) like Property in fuzzy metric spaces

We extend the concept of common (E.A) like property to fuzzy metric space and obtain common fixed point theorems for a pair of self mappings under sufficient contractive type conditions. Our result generalized the result of [2].

\section{PRELIMINARIES}

Definition [17] A binary operation *: $[0,1] \times[0,1] \rightarrow$ $[0,1]$ is called a continuous t-norm if $([0,1], *)$ is an abelian topological monoid with 1 such that $a^{*} b \leq c^{*} d$

Whenever $a \leq c, b \leq d$ for all $a, b, c, d \in[0,1]$ examples of t-norm are

$$
a^{*} b=a b \text { And } a * b=\min \{a, b\}
$$

Definition [16] the 3-tuple (X, M, *) is called a fuzzy metric space if $\mathrm{X}$ is an arbitrary set, $*$ is a continuous t-norm and $\mathrm{M}$ is a fuzzy set on $X^{2} \times(0, \infty)$. Satisfying the following conditions:

(1) $\quad M(x, y, t)>0$

(2) $\quad M(x, y, t)=1$ If and only if $x=y$

(3) $\quad M(x, y, t)=M(y, x, t)$

(4) $\quad M(x, y, t) * M(y, z, s) \leq M(x, z, t+s)$

(5) $M(x, y,):.(0, \infty) \rightarrow[0,1]$ Is continuous, for all $x, y, z \in X$ and $t, s>0$

Let $(X, d)$ be a metric space, and let $a^{*} b=a b$ or $a^{*} b=\min \{a, b\}$.

Let $M(x, y, t)=\frac{t}{t+d(x, y)}$ for all $x, y \in X$ and $t>0$.

Then $\left(X, M,{ }^{*}\right)$ is a fuzzy metric space.

Definition [16] A sequence $\left\{x_{n}\right\}$ in a fuzzy metric space $(X, M, *)$ is said to be a Cauchy sequence if and only if for each $\in>0, t>0$ there exists $x \in N$ such that

$$
M\left(x_{n}, x_{m}, t\right)>1-\in \text { For all } n, m \geq x_{0}
$$

The sequence $\left\{x_{n}\right\}$ is said to converge to a point $x$ in $X$ if for each $\in>0, t>0$ there exists $x_{0} \in N$ such that

$$
M\left(x_{n}, x, t\right)>1-\in \text { For all } x \geq x_{0}
$$

A fuzzy metric space $(X, M, *)$ is said to be complete if every Cauchy sequence in it converges to a point in it.

Definition [4] let A and B maps from a fuzzy metric space $\left(\mathrm{X}, \mathrm{M},{ }^{*}\right)$ into itself the maps $\mathrm{A}$ and $\mathrm{B}$ are said to be compatible (or asymptotically commuting) if for all $\mathrm{t}>\mathrm{o}$

$$
\lim _{n \rightarrow \infty} M\left(A B x_{n}, B A x_{n}, t\right)=1
$$

Whenever $\left\{x_{n}\right\}$ in a sequence in $X$ such That

$$
\lim _{n \rightarrow \infty} A x_{n}=\lim _{n \rightarrow \infty} B x_{n}=z \quad \text { for some } z \in X
$$


Definition [9] let A and B be maps from a fuzzy metric space [fm-space] $(\mathrm{X}, \mathrm{M}, *)$ into itself the maps are said to be weakly compatible if they commute at their coincidence points.

That is $\mathrm{Az}=\mathrm{Bz} \Rightarrow \mathrm{ABz}=\mathrm{BAz}$

Definition [12] let A and B maps from a fuzzy metric space $\left(\mathrm{X}, \mathrm{M},{ }^{*}\right)$ into itself a fuzzy metric space $\left(\mathrm{X}, \mathrm{M},{ }^{*}\right)$ into itself. The maps A and B are said to be semi-compatible,

If for all $\mathrm{t}>0 \lim _{\mathrm{n} \rightarrow \infty} \mathrm{M}\left(\mathrm{ABx}_{\mathrm{n}}, \mathrm{Bz}, \mathrm{t}\right)=1$

Whenever $\left\{x_{n}\right\}$ in a sequence in $X$ such That $\lim _{n \rightarrow \infty} A x_{n}=$ $\lim _{\mathrm{n} \rightarrow \infty} \mathrm{Bx}_{\mathrm{n}}=\mathrm{z}$ for some $\mathrm{z} \in \mathrm{X}$

Note: The semi compatibility of the pair (A, B) need not imply the semi compatibility of $(\mathrm{B}, \mathrm{A})$.

\section{Example [8]}

Let $(X, d)$ be a metric space define $a * b=\min \{a, b\}$ for all $\{x, y\} \in X$ let,

$$
M(x, y, t)=t / t+d(x, y) \text { for all } t>0
$$

And $\mathrm{M}(\mathrm{x}, \mathrm{y}, \mathrm{o})=0$

Than $(\mathrm{X}, \mathrm{M}, *)$ is a fuzzy metric space it is called fuzzy metric space induced by the metric space $(X, d)$.

Lemma [16] $M(x, y$,$) is non decreasing for all x$, $y$ in $X$.

Definition [16] Two self mappings $\mathrm{S}$ and $\mathrm{T}$ of a fuzzy metric space $(\mathrm{X}, \mathrm{M}, *)$ are said to be weakly commuting if $\mathrm{M}(\mathrm{STx}, \mathrm{TSx}, \mathrm{t}) \geq(\mathrm{STx}, \mathrm{TS} x, \mathrm{t})$ for all $\mathrm{t}>0$ and for all $\mathrm{x} \in \mathrm{X}$

Clearly two commuting mappings are weakly commuting.

Definition [15] Let $\mathrm{T}$ and $\mathrm{S}$ be two self mappings of a fuzzy metric space $\left(\mathrm{X}, \mathrm{M},{ }^{*}\right)$ then $\mathrm{S}$ and $\mathrm{T}$ are said to be compatible if $\lim _{n \rightarrow \infty} M\left(S T x_{n}, T S x, t\right)=1$ whenever $\left(\mathrm{x}_{\mathrm{n}}\right)$ is a sequence in $\mathrm{X}$ such that $\lim _{n \rightarrow \infty} S x_{n}=\lim _{n \rightarrow \infty} T x_{n}=x_{0}$

Definition [14] Two self mappings $\mathrm{T}$ and $\mathrm{S}$ of a fuzzy metric space $\left(\mathrm{X}, \mathrm{M},{ }^{*}\right)$ are said to be weakly compatible if they commute at their coincidence points (i.e.) if $\mathrm{Tu}=\mathrm{Su}$ for some $\mathrm{u} \in \mathrm{X}$, then $\mathrm{TSu}=\mathrm{STu}$.

It is easy to see that two compatible maps are weakly compatible.

Definition [12] Let Sand $T$ be two self mappings of a fuzzy metric space $(\mathrm{X}, \mathrm{M}, *)$. We say that $\mathrm{T}$ and $\mathrm{S}$ satisfy E.A. Property, if there exists a sequence $\left\{x_{n}\right\}$ such that

$$
\begin{aligned}
& \lim _{n \rightarrow \infty} T x_{n}=\lim _{n \rightarrow \infty} S x_{n}=x_{0}, \text { For some } x_{0} \in X \text { i.e. } \\
& \lim _{n \rightarrow \infty} M\left(T x_{n}, x_{0}, t\right)=\lim _{n \rightarrow \infty} M\left(S x_{n}, x_{0}, t\right)=1 \quad \text { For all }
\end{aligned}
$$$$
t \in[0, \infty)
$$

Notice that weak compatible and property (E.A) are independent to each other.

Example: Let $\mathrm{X}=[0, \infty)$. Let $\mathrm{M}(\mathrm{x}, \mathrm{y}$, and $\mathrm{t})=\frac{t}{t+x-y}$

Define $T, S: X \rightarrow[0, \infty)$ by $T_{x}=\frac{x}{5}$ and $S_{x}=\frac{2 x}{5}$ for all $x \in X$.

$$
\lim _{n \rightarrow \infty} T x_{n}=\lim _{n \rightarrow \infty} S x_{n}=0 \text { When } X_{n}=\frac{1}{n}
$$

Definition [18] Let $f$ and $g$ be two self mappings of a fuzzy metric space $\left(\mathrm{X}, \mathrm{M},{ }^{*}\right)$. We say that $\mathrm{f}$ and $\mathrm{g}$ satisfy the property E.A. like, if there exists a sequence $\left\{x_{n}\right\}$ such that

$$
\lim _{n \rightarrow \infty} f x_{n}=\lim _{n \rightarrow \infty} g x_{n}=z \text {, For some } z \in X \text { for some }
$$$$
z \in f(x) \text { or } z \in g(x) \text { i.e. } z \in f(x) \cup g(x)
$$

Definition [18] Let A, B, S, T: $X \rightarrow X$ where $X$ is fuzzy metric spaces then the pair $\{\mathrm{A}, \mathrm{S}\}$ and $\{\mathrm{B}, \mathrm{T}\}$ said to satisfy common (E.A) property if there exists two sequences $\left\{\mathrm{x}_{\mathrm{n}}\right\}$ and $\left\{y_{n}\right\}$ in $X$ such that

$$
\begin{aligned}
& \lim _{n \rightarrow \infty} A x_{n}=\lim _{n \rightarrow \infty} S x_{n} \\
& =\lim _{n \rightarrow \infty} T y_{n}=\lim _{n \rightarrow \infty} B y_{n}=z \quad \text { For some z } \in \mathrm{X}
\end{aligned}
$$

Definition [18] Let A, B, S, T: $X \rightarrow X$ where $X$ is fuzzy metric spaces then the pair $\{A, S\}$ and $\{B, T\}$ said to satisfy "common (E.A) like property" if there exists two sequences $\left\{x_{n}\right\}$ and $\left\{y_{n}\right\}$ in $X$ such that

$\lim _{n \rightarrow \infty} A x_{n}=\lim _{n \rightarrow \infty} S x_{n}=\lim _{n \rightarrow \infty} T y_{n}=\lim _{n \rightarrow \infty} B y_{n}=z$

For some $\mathrm{z} \in \mathrm{S}(\mathrm{X}) \cap \mathrm{T}(\mathrm{X})$ and $\mathrm{z} \in \mathrm{A}(\mathrm{X}) \cap \mathrm{B}(\mathrm{X})$

If two mapping satisfy E.A likes property then they satisfies E.A property also .but on the other hand, E.A like property relaxes the condition of containment of ranges and closeness of the range to prove common fixed point theorem.

Lemma [10] If for all $x, y \in X$, to with positive number $\mathrm{q} \in(\mathrm{o}, 1)$ and $\mathrm{M}(\mathrm{x}, \mathrm{y}, \mathrm{qt}) \geq \mathrm{M}(\mathrm{x}, \mathrm{y}, \mathrm{t})$ then $\mathrm{x}=\mathrm{y}$

Example 2.1: $\psi\left(t_{1}, t_{2}, t_{3}, t_{4}\right)=t_{1}-\max \left\{t_{2}, t_{3}, t_{4}\right\}$

\section{MAIN RESULT}

Aalam, Kumar S and Pant B.D. [2] proved the following fixed point theorem in fuzzy metric space.

Theorem3.1: Let $\mathrm{A}, \mathrm{B}, \mathrm{S}$ and $\mathrm{T}$ be self maps of a fuzzy metric space $\left(X, M,{ }^{*}\right)$ satisfying the following conditions

3.1(1)A $(\mathrm{X}) \subseteq \mathrm{T}(\mathrm{X}), \mathrm{B}(\mathrm{X}) \subseteq \mathrm{S}(\mathrm{X})$

3.1(2) $(\mathrm{A}, \mathrm{S})$ and $(\mathrm{B}, \mathrm{T})$ are weakly Compatible pairs

3.1(3)(A, S) or (B, T) satisfy the property $(\mathrm{E}, \mathrm{A})$

3.1(4)For same $\phi \in \emptyset$ and for all $\mathrm{x}, \mathrm{y} \in \mathrm{X}, \mathrm{t}>\mathrm{o}$

$\phi(M(A x, B y, k t), M(S x, T y, t), M(A x, S x, t)$

$$
M(B y, T y, t)) \geq 0
$$

The range of one of the maps A,B,S or T is a complete sub space of $\mathrm{X}$, than $\mathrm{A}, \mathrm{B}, \mathrm{S}, \mathrm{T}$ have a unique common fixed point in $\mathrm{X}$.

We suppose following implicit relations to established a new fixed point the over in fuzzy metric space

\section{A Class of implicit relation:-}

Let $\Psi$ be the set of all real and continuous function s.t $\psi:[0,1]^{4} \rightarrow \mathrm{R}$

Satisfying the following conditions:

(A-1) $\psi$ is non-increasing in thirds argument. 
(A-2) $\psi(\mathrm{u}, 1,1, \mathrm{u}) \geq 0$ or $\psi(\mathrm{u}, 1, \mathrm{u}, 1) \geq 0$ or $\psi(\mathrm{u}, \mathrm{u}, \mathrm{u}, 1) \geq 0$ implies $\mathrm{u} \geq 1$ for all $\mathrm{u} \in[0,1]$

3.2 Theorem: Let $\mathrm{A}, \mathrm{B}, \mathrm{S}$ and $\mathrm{T}$ is self maps of a fuzzy metric space $(\mathrm{X}, \mathrm{M}, *)$ satisfying the conditions:

$3.2(1) \mathrm{A}(\mathrm{X}) \subseteq \mathrm{T}(\mathrm{X}), \mathrm{B}(\mathrm{X}) \subseteq \mathrm{S}(\mathrm{X})$

3.2 (2) (A, S) and (B, T) are weakly Compatible pairs

3.2 (3) (A, S) or (B, T) satisfy the common (E.A) like property and

3.2 (4) for some $\psi \in \Psi$ and for all $\mathrm{x}, \mathrm{y} \in \mathrm{X}, \mathrm{t}>0$

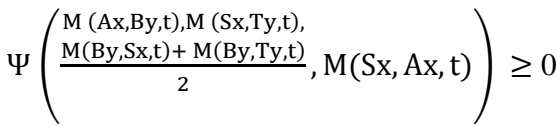

If the range of one of the maps $\mathrm{A}, \mathrm{B}, \mathrm{S}$ or $\mathrm{T}$ is a complete subspace of $\mathrm{X}$,

Than A, B, S and T have a unique common fixed point in $\mathrm{X}$.

Proof: If the pair (A, S) an (B, T) satisfies the common (E.A) like property therefore there exist two sequences $\left\{x_{n}\right\}$ and

$\left\{\mathrm{y}_{\mathrm{n}}\right\}$ in $\mathrm{X}$ such that

$\lim _{n \rightarrow \infty} A x_{n}=\lim _{n \rightarrow \infty} S x_{n}=\lim _{n \rightarrow \infty} T y_{n}=\lim _{n \rightarrow \infty} B y_{n}=z$

For some $\mathrm{z} \in \mathrm{S}(\mathrm{X}) \cap \mathrm{T}(\mathrm{X})$ and $\mathrm{z} \in \mathrm{A}(\mathrm{X}) \cap \mathrm{B}(\mathrm{X})$

Suppose that $z \in S(X) \cap T(X)$ then $z=S u$, for some $u \in X$. now we claim that $\mathrm{Au}=\mathrm{Su}$

We have from Contradiction condition,

$\Psi\left(\begin{array}{c}M\left(A u, B x_{n}, t\right), M\left(S u, T x_{n}, t\right), \\ \frac{M\left(B x_{n}, S u, t\right)+M\left(B x_{n}, T x_{n}, t\right)}{2}, M(S u, A u, t)\end{array}\right) \geq 0$

Letting limit as $\mathrm{n} \rightarrow \infty$ are get

$\Psi\left(\begin{array}{c}\mathrm{M}(\mathrm{Au}, \mathrm{Su}, \mathrm{t}), \mathrm{M}(\mathrm{Su}, \mathrm{Su}, \mathrm{t}), \\ \frac{\mathrm{M}(\mathrm{Su}, \mathrm{Su} t \mathrm{t}) \mathrm{M}(\mathrm{Su}, \mathrm{Su}, \mathrm{t})}{2}, \mathrm{M}(\mathrm{Su}, \mathrm{Au}, \mathrm{t})\end{array}\right) \geq 0$

$\Psi(\mathrm{M}(\mathrm{Au}, \mathrm{Su}, \mathrm{t}), \mathrm{M}(\mathrm{Su}, \mathrm{Su}, \mathrm{t}), \mathrm{M}(\mathrm{Su}, \mathrm{Su}, \mathrm{t}), \mathrm{M}(\mathrm{Su}, \mathrm{Au}, \mathrm{t})) \geq 0$

$\Rightarrow \Psi(\mathrm{M}(\mathrm{Au}, \mathrm{Su}, \mathrm{t}), 1,1, \mathrm{M}(\mathrm{Su}, \mathrm{Au}, \mathrm{t})) \geq 0$

By the first property of implicit relation we get

$\mathrm{M}(\mathrm{Au}, \mathrm{Su}, \mathrm{t}) \geq 1$

Therefore we get

$$
\mathrm{Au}=\mathrm{Su}
$$

The weak compatibility of $\mathrm{A}$ and $\mathrm{S}$ implies $\mathrm{ASu}=\mathrm{SAu}$.

And then $\mathrm{AAu}=\mathrm{ASu}=\mathrm{SSu}$

On the other hand since $\mathrm{A}(\mathrm{X}) \subseteq \mathrm{T}(\mathrm{X})$ and Therefore these exist $\mathrm{v} \in \mathrm{X}$ s.t. $\mathrm{Au}=\mathrm{Tv}$.

Again $\lim _{n \rightarrow \infty} B y_{n}=z \in \mathrm{T}(\mathrm{X})$ then $\mathrm{z}=\mathrm{T}(\mathrm{X})$ for some $\mathrm{v} \in \mathrm{X}$

By contractive condition we get

$\psi\left(\begin{array}{c}M(A u, B v, t), M(S u, T v, t), \frac{M(B v, S u, t)+M(B v, T v, t)}{2}, \\ M(S u, A u, t)\end{array}\right) \geq 0$
$\psi\left(M(T v, B v, t), M(T v, T v, t), \frac{M(B v, T v, t)+M(B v, T v, t)}{2},\right) \geq 0$

$\Psi(\mathrm{M}(\mathrm{Tv}, \mathrm{Bv}, \mathrm{t}), 1, \mathrm{M}(\mathrm{Tv}, \mathrm{Bv}, \mathrm{t}), 1) \geq 0$

Therefore by the property of implicit relation we get

$\mathrm{M}(\mathrm{Tv}, \mathrm{Bv}, \mathrm{t}) \geq 1$

Therefore we get $\mathrm{Tv}=\mathrm{Bv}$ this implies that

$$
\mathrm{Au}=\mathrm{Su}=\mathrm{Tv}=\mathrm{Bv}
$$

The weak compatibility of $\mathrm{B}$ and $\mathrm{T}$ implies that $\mathrm{BTv}=\mathrm{TBv}$ and $\mathrm{TBv}=\mathrm{BTv}=\mathrm{BBv}$

Let us show that $\mathrm{Au}$ is a common fixed point of $\mathrm{A}, \mathrm{B}, \mathrm{S}$ and $\mathrm{T}$ In view of 3.1 (4) contradictive condition,

Putting $\mathrm{x}=\mathrm{Au}, \mathrm{y}=\mathrm{u}$ follows

$\psi\left(\begin{array}{c}M(A A u, A u, t)+M(A A u, A u, t), \frac{M(A u, A A u, t)+M(A u, A u, t)}{2}, \\ M(A A u, A A u, t)\end{array}\right) \geq 0$

$\psi\left(\begin{array}{c}M(A A u, A u, t), M(A A u, A u, t), \\ \frac{M(A u, A A u, t)+M(A u, A u, t)}{2}, 1\end{array}\right) \geq 0$

$\psi\left(M(A A u, A u, t)+M(A A u, A u, t) \frac{M(A A u, A u, t)+1}{2}, 1\right) \geq 0$

Since $\psi$ is non increasing in third argument

And so $M(A A u, A u, t) \geq 1$ [By using implicit relation]

$\mathrm{AAu}=\mathrm{Au}$ Therefore $\mathrm{Au}=\mathrm{AAu}=\mathrm{SAu}$. So $\mathrm{Au}$ is Common fixed point of $\mathrm{A}$ and $\mathrm{S}$.

Similarly we prove that $\mathrm{Bv}$ is a common fixed point of B and $\mathrm{T}$.

Since $\mathrm{Au}=\mathrm{Bv}$ we conclude that $\mathrm{Au}$ is common fixed point of $\mathrm{A}, \mathrm{B}, \mathrm{S}$ and $\mathrm{T}$

The proof is similar when $\mathrm{z} \in \mathrm{S}(\mathrm{X}) \cap \mathrm{T}(\mathrm{X})$.

For uniqueness:

$\mathrm{Au}=\mathrm{Bu}=\mathrm{Tu}=\mathrm{Su}=\mathrm{P} 1$ and $\mathrm{Av}=\mathrm{Bv}=\mathrm{Tv}=\mathrm{Sv}=\mathrm{P} 2$

Then from contradictive condition 3.1(4)

$\psi\left(M(A u, B v, t), M(S u, T v, t), \frac{M(B v, S u, t)+M(B v, T v, t)}{2},\right) \geq 0$

$\psi\left(\begin{array}{c}M\left(P_{1}, P_{2}, t\right), M\left(P_{1}, P_{2}, t\right), \frac{M\left(P_{1}, P_{2}, t\right)+M\left(P_{2}, P_{2}, t\right)}{2}, \\ M\left(P_{1}, P_{1}, t\right)\end{array}\right) \geq 0$

$\psi\left(M\left(P_{1}, P_{2}, t\right), M\left(P_{1}, P_{2}, t\right), \frac{M\left(P_{1}, P_{2}, t\right)+1}{2}, 1\right) \geq 0$

Since $\Psi$ is non increasing in third argument

$\psi\left(M\left(P_{1}, P_{2}, t\right), M\left(P_{1}, P_{2}, t\right) M\left(P_{1}, P_{2}, t\right), 1\right) \geq 0$

Therefore using the property of implicit we get $\mathrm{M}\left(P_{1}, P_{2}, t\right) \geq 1$ 
Therefore we get $\mathrm{P} 1=\mathrm{P} 2$

Therefore common fixed point is unique.

Remark 3.1: By choosing A, B, S, and T suitably, one can derive corollaries involving two or more mapping. As a sample, we deduce the following natural result for a pair of self mappings by setting $\mathrm{B}=\mathrm{A}$ and $\mathrm{T}=\mathrm{S}$ in above theorem:

Corollary3.1: Let $A$ and $S$ be self mappings of a fuzzy metric space $\left(\mathrm{X}, \mathrm{M},{ }^{*}\right)$ satisfying the conditions:

(5) (A, S) satisfy the common (E.A) like property and

(6) For some $\psi \in \psi$ and for all $\mathrm{x}, \mathrm{y} \in \mathrm{X}, \mathrm{t}>0$

$\Psi\left(\begin{array}{l}M(A x, B y, t), M(S x, T y, t), \\ \frac{M(B y, S x, t)+M(B y, T y, t)}{2}, M(S x, A x, t)\end{array}\right) \geq 0$

If pair $(\mathrm{A}, \mathrm{S})$ is weakly compatible then $\mathrm{A}$ and $\mathrm{S}$ have unique common fixed point.

\section{CONCLUSION}

We establish A Common Fixed Point Theorem in Fuzzy Metric Spaces satisfying common (E.A.) like property implicit relations. There are some possible application in real application engineering, economics in dealing with problems which arising in approximation theory, information system, computer science in future scope we can obtain new implicit relation as well as new contradiction to relax conditions.

\section{ACKNOWLEDGMENTS}

Both the authors are thankful to Mr. Rakesh Rathore CEO, Vikrant Group of Institution, Gwalior (M.P) ,India for his kind cooperation and guidance and also thankful to the learned referee for his valuable comments to prepare the paper.

\section{REFERENCES}

[1] Aamri M. and D.E. Motawakil, Some new common fixed point theorem under strict contractive conditions, J.Math. Anal Appli. 270 (2002), Pages 181-188

[2] Aalam I., kumar S. and Pant, B.D. A common fixed point theorem in fuzzy metric space. Bull. Of Math. Analysis and applications, ISSN: 1821-1291. Vol. 2 Issue 4 (2010), Pages 76-82.

[3] Bhardwaj R.K, etal, Some Results on Fuzzy metric spaces, proceeding world congress on Engineering 2011 Vol.1, WCE 2011, July 6-8, 2011 London, U.K.

[4] Chauhan, M.S., Badshah, V.H. and Chouhan V.S. A fixed point theorem for four weakly compatible mappings in fuzzy metric space, int. Journal of math. Analysis, Vol. 4, 2010, no. 6, 273-278.
[5] Geroge A. and P. Veeramani, on some result in Fuzzy metric spaces, Fuzzy sets and systems 64 (1994), 395399

[6] Grabiec M, Fixed points in Fuzzy metric spaces, Fuzzy sets and systems 27 (1988), 385-389

[7] Jungck, G. and Rhoades, B.E,Fixed point for set valued functions without continuity, Indian Journal of pure and Applied Mathematics, 29(1998), 227-238,

[8] I Kramosil and J.Michalek, fuzzy metric and statistical metric spaces, kypernatika 11(1975) m, 336-344

[9] Kumar S. , Fixed point theorems for weakly compatible maps under (E. A) property in fuzzy metric spaces; J. Appl. Math and Informatics Vol. 29 (2011), No. 1-2, PP. 395-405.

[10] S.N. Mishra, N.Sharma and S.L.Singh, Common fixed point of maps on fuzzy metric spaces, int. J. Math, Math Sci.17 (1994) 253-258

[11] V.Pant and R.P.Pant, Fixed points in fuzzy metric spaces for non compatible maps, Soochow J. Math 33(4) (2207) 647-655.

[12] H.K. Pathak, R.R. Lopez and R.K.Verma, A common fixed point theorem using implicit relation and property (E.A.) in metric spaces, Filomat 21(2) (2007) 211-234

[13] Manro , Bhatia S.and Kumar S.,Common fixed point theorem for weakly compatible maps satisfying (E.A) property in intuitionistic fuzzy metric spaces; Punjab University, Journal of mathematics. Vol. 42 (2010) pp. 51-56.

[14] Pathak, H.K., Chang, S.S. and Cho, Y.J., Fixed point theorems for compatible mappings of type (P), Indian Journal of mathematics, Vol 36, No.2, August 1994, and 151-166.

[15] Singh, B. and Jain, S.Semi-compatibility and fixed point theorems in fuzzy metric space using implicit Relations. International Journal of mathematics and mathematical sciences, 16: 2005, 2617-2629.

[16] Singh, B. and Bhadauriya MS, Common fixed point theorem $\epsilon$ chainable fuzzy metric spaces, using implicit relation, International journal of computer application (0975-8887)Volume 39-No.4, February 2012

[17] Wadhwa $\mathrm{k}$ et.al, Impact of (E.A) like property on common fixed point theorem in fuzzy metric spaces, journal of advance study in topology, vol3,no2012,52-59.

[18] Zadeh, L.A, Fuzzy sets Inform and Control, 8 (1965), 338-353. 1965. 